\title{
Prevalence of behavioral disorders in children and early adolescent: An Eastern Indian single center study
}

\author{
Rupa Biswas ${ }^{1}$, Payel Biswas², Gargi Das ${ }^{3}$, Jinia Saha ${ }^{4}$, Shyamal Banerjee ${ }^{5}$, Srijit Ghosh \\ ${ }^{1}$ Associate Professor, ${ }^{2}$ Postgraduate Resident, ${ }^{3,4}$ Senior Resident, ${ }^{5,6}$ Professor, Department of Pediatric Medicine, \\ Calcutta National Medical College and Hospital, Kolkata, West Bengal, India
}

Background: Mental health problems evolving from early childhood to adolescent period affect the processes of adaptation and capability in adulthood. Aims and Objectives: The study aims to study the prevalence of different types of behavioral disorders among children and early adolescents (6-12 years) and detect association between socio-demographic parameters and behavioral disorders as well as detect the behavioral problems for early treatment regarding their child's behavioral problem. Materials and Methods: A cross-sectional retrospective study was conducted in the pediatric OPD and Adolescent Clinic of Calcutta National Medical College from March 2019 to February 2020. 176 patients were included after proper sampling and consent. Semi-structured socio-demographic profile sheet was filled up by parents. Individual child was assessed for various behavioral disorders using the Child Symptom Inventory (CSI)4 parent questionnaire where data were collected from parents by the investigator through a single time interview. Results: Prevalence of Anxiety disorders was highest in our study, with increased incidence in females. Autism in children was found to be associated with their low birth weight. High incidence of disruptive, impulse control and conduct disorder was seen among boys and mainly in children living with single parent and mothers working. Conclusion: The study is based on informants' perceptions of the children's behavior. The study enables understanding of the behavior of children and associated contexts which is essential to make an interventional plan tailored to the needs of the child in the long run.
Access this article online

Website:

http://nepjol.info/index.php/AJMS

DOI: $10.3126 /$ ajms.v13i2.40808

E-ISSN: 2091-0576

P-ISSN: 2467-9100

Copyright (c) 2022 Asian Journal of Medical Sciences

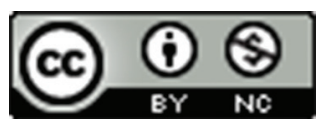

This work is licensed under a Creative Commons Attribution-NonCommercial 4.0 International License.

Key words: Adolescent; Behavioral disorder; Children; CSI-4; DSM-4

\section{INTRODUCTION}

Mental health problems evolve from early childhood to adolescent period. These affect the processes of adaptation and subsequent adult roles; for which mental health problems in young children must be addressed as a priority of public health interest. Globally, one in every five children and adolescent suffer from a mental disorder. It is expected that by 2020 childhood neuropsychiatric disorder will rise to over $50 \%$ and will become one of five most common reasons of morbidity, mortality, and disability among children. ${ }^{1}$

Adolescents suffer from various forms of internal conflicts while growing up, which might impair normal psychosocial development. Lack of attention to the mental wellbeing of these population during the phase of socialization, may lead to mental health consequences that may persist throughout life and reduces the capacity of societies' economic productivity. ${ }^{2,3}$ Early identification helps in early recovery and subsequently leads the developmental trajectories into a better and healthier adaptive path. In the Indian perspectives, $14-40 \%$ of adolescent population is assumed to be suffering from mental health problems. ${ }^{4}$

The application of diagnostic interviews and statistical methods for determining prevalence and correlates of mental disorders, have established the prevalence of mental disorders, correlates and risk factors for mental disorders, 
patterns of comorbidity, and service patterns in developed countries. ${ }^{5}$ In contrast, there has been wide disparity in the reported prevalence rates of mental disorders in Indian studies among these groups attributed to methodological differences and unspecified clinical criteria for case ascertainment. ${ }^{6}$

\section{Aim and objectives \\ Primary objectives}

1. To study the prevalence of different types of behavioral disorders among children and early adolescents aged between 6 and 12 years.

2. To study the association between socio-demographic parameters and behavioral disorders in these children.

\section{Secondary objectives}

1. To detect these behavioral problems early.

2. To treat these behavioral problems accordingly.

3. To counsel the parents regarding their child's behavioral problem for better compliance.

\section{MATERIALS AND METHODS}

\section{Study design}

An observational, cross-sectional study was conducted in the pediatric OPD and Adolescent Clinic, Calcutta National Medical College and Hospital, Kolkata, West Bengal, after proper ethical committee permission. Data collection was done from March 2019 to February 2020 and included children and early adolescents aged between 6 and 12 years with suspected behavioral problems. Consecutive sampling method was followed, where consecutive child of both sexes who attended the clinic within the study period were considered for the study. A total of 254 children were thoroughly evaluated by detailed history and clinical examination to rule out any organic cause. Then, they were referred to the clinical psychologist for IQ assessment to rule out Intellectual disability. 78 children diagnosed with intellectual disability were excluded from the study. The remaining 176 children were our study samples. Each child and their parents were interviewed once during the study period.

Children with any chronic organic illnesses, neurological disabilities, and refusal of consent were excluded.

\section{Study variables and tools}

1. Self-designed, semi-structured socio-demographic profile sheet was used to collect the background sociodemographic information.

2. Child Symptom Inventory (CSI)-4: The CSI- $4{ }^{7}$ is a behavior rating scale that is referenced by DSM-IV-R for emotional and behavioral disorders between 5 and 12 years old. There are parent (97 items) and teacher versions (77 items). The "CSI-4 Parent-Checklist" contains screens for 15 emotional and behavioral disorders, and the "CSI-4 Teacher Checklist" contains screens for 13 emotional and behavioral disorders. The CSI-4 can be scored to derive symptom count scores or symptom severity scores. In our study, the parents of the children were interviewed by CSI-4 Parent-Checklist and each parent rates each item on a 4-point response scale, indicating frequently the symptom is observed. The CSI-4 contains symptom-categories for DSM-IV disorders: such as ADHD of Inattentive type, ADHD of HyperactiveImpulsive type, ADHD of Combined type; ODD, $\mathrm{CD}, \mathrm{GAD}$, social phobia, SAD; MDD; dysthymic disorder; schizophrenia and autistic disorder. The CSI-4 also contains single items to screen for simple phobias, obsessions, compulsions, motor tics, vocal tics, enuresis, and encopresis. Administration time is between 10 and $15 \mathrm{~min}$. There are two scoring procedures: "Symptom Count (categorical) scores, which use scores of 0 (never/sometimes) or 1 (often/ very often), and Symptom Severity (dimensional) scores, which use scores of 0 (never), 1 (sometimes), 2 (often), or 3 (very often)." Symptom Severity scores are simply the sum of the item scores for a particular symptom category. For symptom count scores, a specific symptom is generally considered to be a clinically relevant problem if it is rated as occurring "often" or "very often." When the symptom count score is equal to or greater than the number of symptoms specified by DSM-IV as being necessary for a diagnosis, the child receives a Screening Cutoff score of "yes" for the disorder. Although the CSI4 contains the behavioral symptoms of disorders, it does not include additional diagnostic criteria (e.g., age of onset of symptoms, impairment of functioning).

\section{Study procedure}

The study subjects were included as per inclusion criteria. The socio-demographic profile sheet was filled up by parents and then individual child was assessed for various behavioral disorders using the CSI-4 parent questionnaire where data were collected from parents by the investigator through a single time interview.

\section{Statistical analysis}

Statistical analyzes were performed using the software IBM-SPSS Statistics, Version 22.0. Chi square test was used to check the significance of difference of proportions. 
Student's $t$ test and one-way ANOVA were used to check the significance of difference between two and more than two means.

\section{RESULTS}

Out of 176 children, mean age was calculated to be $9.23 \pm 1.718$. The age-distribution of participants was as follows: $6-9$ years, $58.5 \%$; $10-12$ years, $41.5 \%$. The gender-wise distribution of participants showed: Males, $64.2 \%$; Females, 35.8\%. The religion-wise distribution of participants showed: Hindus, $17.6 \%$; Muslims, $82.4 \%$. $13.1 \%$ of the population resided in urban cities, $46 \%$ in urban slums while $40.9 \%$ resided in villages.

The distribution of participants showed:

- Family type: Joint family, $65.9 \%$; Nuclear family, 35.1\%

- Socio-economic status as per Modified B G Prasad scale: Low, 18.2\%; Lower Middle, 68.2\% and Middle $13.6 \%$

- Birth weight: low birth weight, $25 \%$; normal birth weight, $53.9 \%$ and data not available $21.1 \%$

- Single parents $23.9 \%$

- $75 \%$ had their mothers non-working

$17.1 \%$ had a family history of mental illness among the first-degree relatives.

\section{DISCUSSION}

The aim of our study was to determine the prevalence of different behavioral disorders occurring in children and early adolescents attending our hospital. In our study, $30.70 \%$ of children were found to have Intellectual Disability of some grade. Similar prevalence of Intellectual Disability (30.97\%) had been seen in a study by Chaudhury et al., ${ }^{8}$ which concluded that children with Intellectual-Disability are at significantly increased risk of certain psychiatric disorders.

The mean age of our study population is 9.23 years $( \pm 1.718)$ with $113(64.2 \%)$ boys and $63(35.8 \%)$ girls. The predominance of male children can be explained by the fact that, attention is often given more to male child by Indian parents resulting in prompt identification $103(58.5 \%)$ children are in the age group 6-9 years and $73(41.5 \%)$ were early adolescents (10-12 years). Studies have noted differences in psychiatric problems related to age. ${ }^{10}$

In our study, $145(82.4 \%)$ patients were Muslims, while $31(17.6 \%)$ were Hindus. $40.1 \%$ children came from rural background, $46 \%$ from urban slum, $13.1 \%$ from urban area. One limitation in our study was the inability to detect the religious correlation with each patient's problem due to the

\begin{tabular}{lcc}
\multicolumn{3}{l}{$\begin{array}{l}\text { Table 1: Distribution of total number of samples } \\
\text { as per the individual behavioral disorders } \\
\text { diagnosed in the study population }(\mathbf{n = 1 7 6 )}\end{array}$} \\
\hline Behavioral disorders & Frequency $(\mathbf{n})$ & Percentage \\
\hline ADHD & 31 & 17.6 \\
Autism & 16 & 9.1 \\
Conduct disorder & 8 & 4.8 \\
Oppositional defiant disorder & 10 & 5.7 \\
Generalized anxiety disorder & 36 & 20.5 \\
Separation anxiety disorder & 5 & 2.8 \\
Social anxiety & 3 & 1.7 \\
Specific phobia & 2 & 1.1 \\
Obsessive-compulsive disorder & 2 & 1.1 \\
Post-traumatic stress disorder & 1 & 0.6 \\
Somatoform disorder & 1 & 0.6 \\
TIC disorder & 2 & 1.1 \\
Enuresis & 2 & 1.1 \\
Undiagnosed & 57 & 32.4 \\
\hline
\end{tabular}

\begin{tabular}{lcc}
$\begin{array}{l}\text { Table 2: Distribution of study population } \\
\text { according to the different categories } \\
\text { of behavioral disorders as per DSM-V }\end{array}$ \\
$\begin{array}{l}\text { blassification }(\mathbf{n = 1 7 6 )} \\
\text { cliserden }\end{array}$ & Frequency & Percentage \\
\hline Behavioral disorders & 47 & 26.7 \\
\hline $\begin{array}{l}\text { Neurodevelopmental disorders } \\
\text { Anxiety disorders }\end{array}$ & 46 & 26.1 \\
$\begin{array}{l}\text { Disruptive, impulse control and } \\
\text { conduct disorder }\end{array}$ & 18 & 10.2 \\
$\begin{array}{l}\text { Others } \\
\text { Undiagnosed }\end{array}$ & 8 & 4.6 \\
\hline
\end{tabular}

record-based nature of our study, considering some mental illnesses are known to be associated with hyper-religiosity. ${ }^{11}$

Table 1 shows Distribution of total number of samples as per the individual behavioral disorders diagnosed in the study population $(\mathrm{n}=176)$

Table 2 shows Distribution of study population according to the different categories of behavioral disorders as per DSM-V classification $(\mathrm{n}=176)$

Table 3 shows Association between various demographic factors and different behavioral disorders.

About $65.9 \%$ of the children in our study stay in a joint family and majority of them belonged to a lower middle-income group (68.2\%) It is within the family the child learns the basic rules of socialization. In our study, $76.1 \%$ of the children live with both parents and $23.9 \%$ are raised by single parent. The child and family tasks usually are guided by two parents; but when it becomes a responsibility of one, such as family roles and functioning can become chaotic. In our study, $25 \%$ of the mothers are currently working, while the rest $75 \%$ are homemakers. ${ }^{12}$ 


\section{Table 3: Association between various demographic factors and different behavioral disorders}

\begin{tabular}{|c|c|c|c|c|c|}
\hline \multirow{2}{*}{$\begin{array}{l}\text { 1. Gender of the } \\
\text { patients }\end{array}$} & \multirow{2}{*}{\multicolumn{2}{|c|}{ Behavioral disorders }} & \multicolumn{2}{|c|}{ Demographic-parameter } & \multirow{2}{*}{$\begin{array}{l}\text { Statistical } \\
\text { significance }\end{array}$} \\
\hline & & & MALE & FEMALE & \\
\hline & \multicolumn{5}{|l|}{ ADHD } \\
\hline & \multicolumn{2}{|l|}{ Present } & 22 & 09 & $\mathrm{df}=0.749$ \\
\hline & \multicolumn{2}{|l|}{ Absent } & 91 & 54 & $P=0.387$ \\
\hline & \multicolumn{5}{|l|}{ Autism } \\
\hline & \multicolumn{2}{|l|}{ Present } & 13 & 03 & $\mathrm{df}=2.225$ \\
\hline & \multirow{2}{*}{\multicolumn{2}{|c|}{$\begin{array}{l}\text { Absent } \\
\text { Anxiety disorder }\end{array}$}} & 100 & 60 & $P=0.136$ \\
\hline & & & & \\
\hline & & & 22 & 24 & $\mathrm{df}=7.269$ \\
\hline & \multicolumn{2}{|c|}{ Absent } & 91 & 39 & $P=0.007^{*}$ \\
\hline & \multicolumn{5}{|c|}{$\begin{array}{l}\text { Disruptive/impulse control/Conduct } \\
\text { disorder }\end{array}$} \\
\hline & \multicolumn{2}{|c|}{ Present } & 16 & 02 & $d f=5.316$ \\
\hline & \multicolumn{2}{|l|}{ Absent } & 97 & 61 & $P=0.021^{*}$ \\
\hline \multirow[t]{12}{*}{ 2. Religion } & & & HINDU & MUSLIM & \\
\hline & \multicolumn{2}{|l|}{ Present } & 08 & 23 & $\mathrm{df}=1.740$ \\
\hline & \multicolumn{2}{|l|}{ Absent } & 23 & 122 & $P=0.187$ \\
\hline & Autism & & & & \\
\hline & Present & & 05 & 11 & $\mathrm{df}=2.255$ \\
\hline & Absent & & 26 & 134 & $P=0.133$ \\
\hline & Anxiety-disorder & & & & \\
\hline & Present & & 08 & 38 & $\mathrm{df}=0.002$ \\
\hline & Absent & & 23 & 107 & $P=0.963$ \\
\hline & $\begin{array}{l}\text { Disruptive/impulse con } \\
\text { disorder }\end{array}$ & & & & \\
\hline & Present & & 04 & 14 & $\mathrm{df}=0.293$ \\
\hline & Absent & & 27 & 131 & $P=0.588$ \\
\hline 3. Type of family & & & JOINT & NUCLEAR & \\
\hline & ADHD & & & & \\
\hline & Present & & 17 & 14 & $d f=2.052$ \\
\hline & Present & & 07 & 09 & $\mathrm{df}=3.846$ \\
\hline & Absent & & 109 & 51 & $P=0.050$ \\
\hline & Anxiety disorder & & & & \\
\hline & Present & & 31 & 15 & $\mathrm{df}=0.061$ \\
\hline & Absent & & 85 & 45 & $P=0.805$ \\
\hline & $\begin{array}{l}\text { Disruptive/impulse con } \\
\text { disorder }\end{array}$ & & & & \\
\hline & Present & & 11 & 07 & $\mathrm{df}=0.205$ \\
\hline & Absent & & 105 & 53 & $P=0.650$ \\
\hline 4. Area of residence & & RURAL & URBAN-SLUM & URBAN & \\
\hline & ADHD & & & & \\
\hline & Present & 14 & 12 & 5 & $\mathrm{df}=0.873$ \\
\hline & Absent & 59 & 68 & 18 & $P=0.646$ \\
\hline & Autism & & & & \\
\hline & Present & 4 & 9 & 3 & $\mathrm{df}=1.924$ \\
\hline & Absent & 68 & 72 & 20 & $P=0.382$ \\
\hline & Anxiety disorder & & & & \\
\hline & Present & 03 & 34 & 09 & $\mathrm{df}=6.562$ \\
\hline & Absent & 69 & 47 & 14 & $P=0.038^{*}$ \\
\hline & Disruptive/impulse con & & & & \\
\hline & Conduct disorder & & & & \\
\hline & Present & 9 & 8 & 1 & $\mathrm{df}=1.282$ \\
\hline & Absent & 63 & 73 & 22 & $P=0.527$ \\
\hline
\end{tabular}




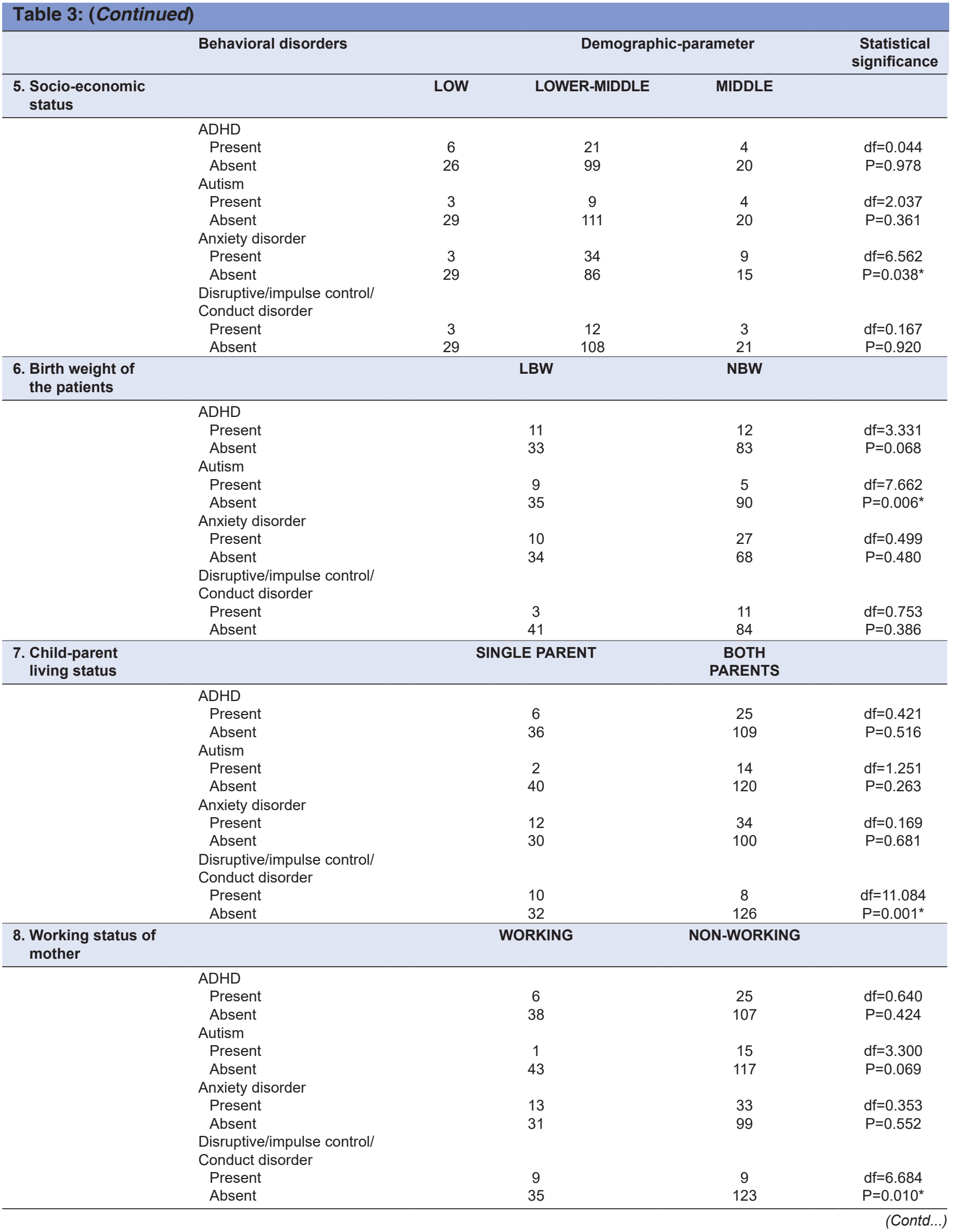




\begin{tabular}{|c|c|c|c|c|}
\hline & \multirow[t]{2}{*}{ Behavioral disorders } & \multicolumn{2}{|c|}{ Demographic-parameter } & \multirow{2}{*}{$\begin{array}{l}\text { Statistical } \\
\text { significance }\end{array}$} \\
\hline \multirow[t]{14}{*}{$\begin{array}{l}\text { 9. Family history of } \\
\text { mental illness }\end{array}$} & & Positive & Negative & \\
\hline & ADHD & & & \\
\hline & Present & 6 & 25 & $\mathrm{df}=0.142$ \\
\hline & Absent & 24 & 121 & $P=0.706$ \\
\hline & Autism & & & \\
\hline & Present & 03 & 13 & $\mathrm{df}=0.036$ \\
\hline & Absent & 27 & 133 & $P=0.849$ \\
\hline & Anxiety disorder & & & \\
\hline & Present & 8 & 38 & $\mathrm{df}=0.005$ \\
\hline & Absent & 22 & 108 & $P=0.942$ \\
\hline & Disruptive/impulse control/ & & & \\
\hline & Conduct disorder & & & \\
\hline & Present & 5 & 13 & $\mathrm{df}=1.633$ \\
\hline & Absent & 25 & 133 & $P=0.201$ \\
\hline
\end{tabular}

Low birth weight (LBW) is seen as a common perinatal risk factor of $\mathrm{ADHD}$, autism, generalized anxiety in previous studies. ${ }^{13,14}$ In our study, $25 \%$ of the children were LBW. However, there was under reporting of LBW, as birth weight was not recorded in many home delivery cases and cases where parents failed to recall. In $17.1 \%$ of the children in our study a positive family history of a mental illness was present. Parental mental illness can be associated with reduced family functioning. In a study by Slatcher and Trentacosta, ${ }^{15}$ an association between parental depressive symptoms and behavioral disorders of their children in daily life.

In our study, the highest prevalence was seen of anxiety disorders (26.1\%), followed by ADHD (17.6\%), disruptive, impulse control and conduct disorder $(10.2 \%)$ and autism (9.1\%). These findings are like a study conducted in Goa, showing that the most common diagnoses were anxiety disorders, depressive disorder, behavioral disorder, and attention-deficit hyperactivity disorder. ${ }^{16}$ However, in our study, $32.4 \%$ of the children with some suspected behavioral problems went undiagnosed and needs further evaluation. The overall prevalence of anxiety disorders in this study is $26.1 \%$, slightly higher than the findings by Nawarathna et al., ${ }^{17}$ where the prevalence of anxiety disorders was $18.9 \%$. Of the 46 individuals with anxiety disorders, 3 have social anxiety, 2 have specific phobia, 5 had Separation Anxiety Disorder and 36 had Generalized Anxiety Disorder. In our study $38.1 \%$ of the girls are diagnosed to have anxiety disorders, which is significantly higher than the boys. This finding is consistent with the National Comorbidity Survey (conducted from 1990 to 1992) findings of lifetime prevalence rates for any anxiety disorder of $30.5 \%$ for women and $19.2 \%$ for men. ${ }^{18}$ Similar findings was also noted in another Indian study ${ }^{17}$ where $27.1 \%$ of the girls suffered from anxiety disorders. Anxiety disorders are also found to be significantly more in children from lower-middle income group and urban-slum children compared to those from rural background.

The prevalence of ADHD is $17.6 \%$ which is less compared to $35.10 \%$ prevalence found in a study by Mitra and Ray. ${ }^{19}$ However, in another study by Nawarathna et al., ${ }^{17}$ the prevalence of ADHD was found to be $8.2 \%$. Prevalence of autism in our clinic-based study is $9.1 \%$ which is much higher compared to various community-based studies. ${ }^{20,21}$ There might be an under- or over-estimation of the prevalence of ASD in different geographic distributions due to this variability in assessment.

LBW of children had been associated with reported problems of inattention and hyperactivity, thought problems, social and peer problems. In our study, a significant association is seen between Autism and low birth weight of the children, which is in parity with findings in other studies as well. In a study by Hack et al., ${ }^{13}$ extreme low birth weight children had significantly higher scores than normal birth-weight children for the inattentive, hyperactive, and combined types of ADHD, as per CSI-4 Severity Scores. They also had significantly higher scores for generalized anxiety and autistic disorders. The significant differences were evident among both girls and boys apart from generalized anxiety that pertained only to girls.

In our study disruptive, impulse control and conduct disorder group includes conduct disorder $(n=8)$ and ODD $(n=10)$. The overall prevalence of this group is $10.2 \%$. Prevalence of CD varies among the Indian studies, Deivasigamani (11.13\%), ${ }^{22}$ and Sarkar et al., $(7.1 \% .)^{23}$ had reported a prevalence of $4.94 \%$ in a retrospective clinical study. Sarkhel et al., ${ }^{25}$ had reported 
a prevalence rate of $4.58 \%$ school going population. The prevalence of conduct disorder was significantly high among the boys $(14.16 \%)$ compared to the girls $(3.17 \%)$ in our study. In a study by Jayaprakash et al., ${ }^{24}$ significant male dominance $(88.3 \%$ ) with boy girl ratio 7.5:1 was seen. In another study by Sarkhel et al., ${ }^{25}$ the ratio of conduct disorder of boys to girls was 4.5:1 which is like our findings. Furthermore, in our study, the overall prevalence of these disorders is significantly more in children who are living with single parent $(23.8 \%)$ and those who have working mother's $(20.5 \%)$. This might be since working women may not be able to provide care with the same intensity to their children as non-working women. ${ }^{17}$

\section{Limitations of the study}

The study sample was taken from a single clinical setting rather than from the community. Multicentric, community based study needs to be conducted to estimate the exact disease prevalence.

\section{CONCLUSION}

The study conducted toward identification of behavioral disorders in children and the early adolescent population. Being a hospital-based study, it has its limitations of not being representative of the community. Many factors which may directly or indirectly influence the mental health of children remains unexplored and warrants a scope for further research.

\section{ACKNOWLEDGMENT}

The authors express gratitude to all the doctors and colleagues of the department of Pediatric Medicine and Psychiatry, Calcutta National Medical College.

\section{REFERENCES}

1. van Landeghem $\mathrm{K}$ and Hess CA. Children's Mental Health: An Overview and Key Considerations for Health System Stakeholders. Washington, DC: National Institute for Health Care Management Research and Educational Foundation; 2005.

2. World Health Organization. The World Health Report 2001: Mental Health: New Understanding, New Hope. Geneva: World Health Organization; 2001. Available from: https://www.apps. who.int/iris/handle/10665/42390

3. Wittchen HU, Nelson CB and Lachner G. Prevalence of mental disorders and psychosocial impairments in adolescents and young adults. Psychol Med. 1998;28(1):109-126. https://doi.org/10.1017/s0033291797005928

4. Arumugam B, Rajendran S and Nagalingam S. Mental health problems among adolescents and its psychosocial correlates. Indian J Res. 2013;2:284-287.
5. Srinath S, Girimaji SC, Gururaj G, Seshadri S, Subbakrishna DK, Bhola $P$, et al. Epidemiological study of child and adolescent psychiatric disorders in urban and rural areas of Bangalore, India. Indian J Med Res. 2005;122(1):67-79.

6. Merikangas KR, Nakamura EF and Kessler RC. Epidemiology of mental disorders in children and adolescents. Dialogues Clin Neurosci. 2009;11(1):7-20.

https://doi.org/10.31887/dcns.2009.11.1/krmerikangas

7. Gadow, K. D., Sprafkin, J., Salisbury, H., Schneider, J., \& Loney, J. (2004). Further Validity Evidence for the Teacher Version of the Child Symptom Inventory-4. School Psychology Quarterly, 19(1), 50-71. https://doi.org/10.1521/scpq.19.1.50.29408 https:// psycnet.apa.org/record/2004-14241-003

8. Chaudhury S, Prasad PL, Zacharias R, Madhusudan T and Saini R. Psychiatric morbidity pattern in a child guidance clinic. Med J Armed Forces India. 2007;63(2):144-146. https://doi.org/10.1016/S0377-1237(07)80059-1

9. Chandola, R. Loss of parents and its effect on children's personality development. Int J Recent Sci Res. 2017;8:2140921411. https://doi.org/10.24327/ijrsr.2017.0811.1068.

10. Conger RD and Donnellan MB. An interactionist perspective on the socioeconomic context of human development. Annu Rev Psychol. 2007;58:175-199. https://doi.org/10.1146/annurev.psych.58.110405.085551

11. Curlin FA, Lawrence RE, Odell S, Chin MH, Lantos JD, Koenig HG, et al. Religion, spirituality, and medicine: Psychiatrists' and other physicians' differing observations, interpretations, and clinical approaches. Am J Psychiatry. 2007;164(12):1825-1831. https://doi.org/10.1176/appi.ajp.2007.06122088

12. Ribeiro M. Children and Divorce. Lisbon: Editorial Presence. 2007. https://doi.org/10.1051/shsconf/20185602002

13. Hack M, Taylor HG, Schluchter M, Andreias L, Drotar D and Klein N. Behavioral outcomes of extremely low birth weight children at age 8 years. J Dev Behav Pediatr. 2009;30(2):122130.

https://doi.org/10.1097/DBP.0b013e31819e6a16

14. Bhutta AT, Cleves MA, Casey PH, Cradock MM and Anand KJ. Cognitive and behavioral outcomes of school-aged children who were born preterm: A meta-analysis. JAMA. 2002;288(6):728-737. https://doi.org/10.1001/jama.288.6.728

15. Slatcher RB and Trentacosta CJ. A naturalistic observation study of the links between parental depressive symptoms and preschoolers' behaviors in everyday life. J Fam Psychol. 2011;25(3):444-448 https://doi.org/10.1037/a0023728

16. Pillai A, Patel V, Cardozo P, Goodman R, Weiss HA and Andrew G. Non-traditional lifestyles and prevalence of mental disorders in adolescents in Goa, India. $\mathrm{Br} \mathrm{J}$ Psychiatry. 2008;192(1):45-51. https://doi.org/10.1192/bjp.bp.106.034223

17. Nawarathna SC, Subba SH and Guha A. Clinico-epidemiological profile of psychiatric disorders among children in a tertiary care hospital of Southern India. J Clin Diagn Res. 2016;10(3):VC05VC08. https://doi.org/10.7860/jcdr/2016/16375.7491

18. Kessler RC, McGonagle KA, Zhao S, Nelson CB, Hughes $M$, Eshleman $S$, et al. Lifetime and 12-month prevalence of DSM-III-R psychiatric disorders in the United States: Results from the National Comorbidity Survey. Arch Gen Psychiatry. 1994;51(1):8-19. 
https://doi.org/10.1001/archpsyc.1994.03950010008002

19. Mitra $S$ and Ray KA. The familial and other environmental risk factors in children with attention deficit hyperactivity disorder. J Psychol Med. 2013;14(2):118-123. Available from: https:/l www.amhonline.org/article.asp?issn=2589-9171;year=2013; vol ume $=14$; issue $=2 ;$;page $=118$; epage $=123$; aulast $=$ mitra;type $=0$

20. Nair MC, Nair GH, Beena M, Princly P, Chandran SA, George B, et al. CDC Kerala 16: Early detection of developmental delay/ disability among children below $6 \mathrm{y}$-a district model. Indian $\mathrm{J}$ Pediatr. 2014;81(2):151-155.

https://doi.org/10.1007/s12098-014-1589-y

21. Poovathinal SA, Anitha $A$, Thomas $R$, Kaniamattam $M$, Melempatt N, Anilkumar A, et al. Prevalence of autism spectrum disorders in a semiurban community in South India. Ann Epidemiol. 2016;26(9):663-5.e8. https://doi.org/10.1016/j.annepidem.2016.07.003

22. Deivasigamani TR. Psychiatric morbidity in primary school children-an epidemiological study. Indian J Psychiatry. 1990;32(3):235-240.

23. Sarkar $A B$, Kapur $M$ and Kaliaperumal VG. The prevalence and pattern of psychological disturbance in schoolgoing middle childhood children. NIMHANS J. 1995;13(1):33-41.

24. Jayaprakash R, Rajamohanan K, Anil P. Determinants of symptom profile and severity of conduct disorder in a tertiary level pediatric care set up: A pilot study. Indian journal of psychiatry. 2014 Oct;56(4):330. DOI: 10.4103/0019-5545.146511

25. Sarkhel S, Sinha VK, Arora M and DeSarkar P. Prevalence of conduct disorder in schoolchildren of Kanke. Indian J Psychiatry. 2006;48(3):159-164.

https://doi.org/10.4103/0019-5545.31579

Authors Contribution:

RB-Analysis of data, taking patient consent forms and revising manuscript; PB- Data collection and attending physicians in diagnosing and treating patients at the clinic; GD- Revising manuscript; JS- Data analysis, writing of manuscript; SB- Clinical physician from pediatric point of view; SG- Clinical physician from psychiatric point of view, assisted in planning of study. All authors have checked and approved the manuscript before submission to the journal

Work attributed to:

Calcutta National Medical College and Hospital, 32 Gorachand Road, Beniapukur, Kolkata - 700 014, West Bengal, India

Orcid ID:

Rupa Biswas - (1) https://orcid.org/0000-0003-3126-2348

Payel Biswas - (1) https://orcid.org/0000-0003-4027-5052

Gargi Das - (1) https://orcid.org/0000-0001-6658-5097

Jinia Saha - https://orcid.org/0000-0003-2710-1082

Shyamal Banerjee - (10) https://orcid.org/0000-0002-3320-964X

Srijit Ghosh - io https://orcid.org/0000-0002-6435-6167

Source of Support: Nil, Conflicts of Interest: None declared. 